\title{
Molecular Genetic Testing in Cystinuria
}

\author{
Thomas Eggermann¹, Sabrina Spengler ${ }^{1}$, Julia Wirth ${ }^{1}$ and Sven Lahme ${ }^{2}$ \\ ${ }^{1}$ Institute of Human Genetics, RWTH Aachen, Germany \\ ${ }^{2}$ St. Trudpert Hospital, Pforzheim, Germany
}

KEYWORDS Cystinuria. SLC3A1. SLC7A9. Mutation Testing

\begin{abstract}
Cystinuria (OMIM 220100) is caused by the defective transport of cystine and the dibasic amino acids in the proximal renal tubule and in the epithelial cells of the gastrointestinal tract. We analysed a cohort of 26 unrelated cystinuria patients diagnosed on the basis of stone formation. Direct sequencing of all coding regions and exon-intron boundaries of the SLC3A1 and SLC7A9 genes allowed us to identify 26 different mutations in 23 out of the 26 patients, in total they accounted for 40 affected chromosomes. Three of the 26 are novel mutations, two in SLC3A1 and one in SLC7A9. Interestingly, two of our patients carried three mutations in SLC3A1 each, one patient was mixed heterozygous for SLC3A1 and SLC7A9 mutations. In summary, these findings expand the spectrum of SLC3A1 and SLC7A9 mutations and confirm the heterogeneity and complexity of cystinuria. If we assume an autosomal recessive inheritance of the disease, our detection rate was $88.5 \%$ and thereby relatively high in comparison to other studies. Nevertheless we have to consider that at least SLC7A9 mutations are often dominant, we therefore think that our effective detection rate is higher. Additionally, the broad pathophysiological consequences of SLC7A9 mutations make an individual prognosis and genetic counselling difficult.
\end{abstract}

\section{INTRODUCTION}

Cystinuria (OMIM 220100) is an inherited renal disease characterised by the defective transport of cystine, lysine, ornithine and arginine in the proximal tubule and in the epithelial cells of the gastrointestinal tract. The resulting urinary hyperexcretion of cystine leads to precipitation in the distal tubule and formation of cystine stones. The prevalence ranges between 1 in 2,500 and 1 in 100,000 (for review: Palacin et al. 2001). While cystinuria is rare in adults, cystine stones represent $4-8 \%$ of renal stones in children.

So far, two genes responsible for cystinuria have been identified: SLC3A1 (chromosome $2 p 21$ ) encodes the heavy subunit rBAT of the renal $\mathrm{b}^{0,+}$ transporter while SLC7A9 (chromosome 19q12) encodes the light subunit $b^{0,+} A T$ (Fig. 1) (Calonge et al. 1994; International Cystinuria Consortium 1999).

Historically, the classification of cystinuria was based on the urinary excretion pattern of heterozygotes. Type I heterozygotes show a normal urinary excretion of all amino acids, in type

Corresponding Author:

Thomas Eggermann, Ph.D.

Institute of Human Genetics, University Hospital, RWTH Aachen Pauwelsstr. 30,

D-52074 Aachen, Germany

Phone: +49 2418088008

Fax: +49 2418082394

E-mail: teggermann@ukaachen.de
II and III heterozygotes an increased excretion of cystine and the dibasic amino acids can be observed (Rosenberg et al. 1964). After identification of the molecular basis of the disease a new molecular classification was proposed: the autosomal recessively inherited type I cystinuria which is mainly caused by SLC3A1 mutations, and the autosomal incomplete dominant nontype I cystinuria associated with SLC7A9 mutations (formerly types II and III). However, the identification of single SLCBA1 mutations causing non-type I cystinuria and of recessive SLC7A9 mutations lead to a new strictly molecular classification (Dello Strogolo et al. 2002) which does not include the biochemical phenotype: type A cystinuria represents SLC3A1 mutations, and type B cystinuria includes SLC7A9 mutations. Thus, three genotypes can be delineated: $\mathrm{AA}, \mathrm{BB}$, and in rare cases mixed cystinuria $\mathrm{AB}$.

In addition to the classical cystinuria phenotype there are some reports on patients with the hypotonia-cystinuria syndrome. In this autosomal recessive disorder microdeletions of the two contiguous genes SLC3A1 and PREPL in 2p21 are not only associated with cystinuria but also with neonatal hypotonia, failure to thrive and growth retardation (for review: Martens et al. 2007).

Here we report on our molecular findings in 26 cystinuria patients and the difficulties to interpret the genetic data in respect to prognosis and genetic counselling. 


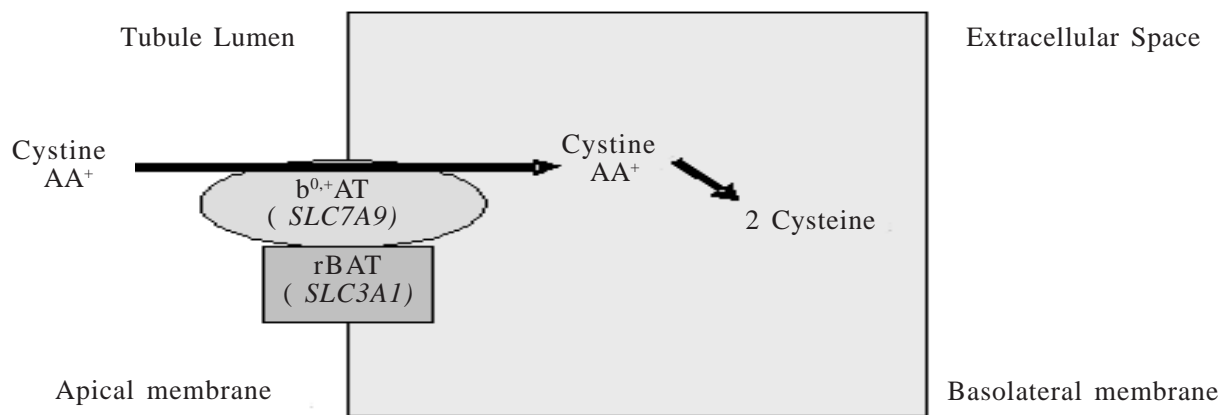

Fig. 1. Schematic drawing of the physiological function of the rBAT and b0,+AT amino acid transport system encoded by SLC3A1 and SLC7A9.

Table 1: Results from molecular genetic testing in the cystinuria patient cohort

\begin{tabular}{|c|c|c|c|c|}
\hline Patient & Ethnic origin & SLC3A1 mutations & SLC7A9 mutations & Cystinuria type \\
\hline 104 & German & & $\begin{array}{l}\text { G105R } \\
\text { IVS5+2T/C }\end{array}$ & BB \\
\hline 156 & German & & $\begin{array}{l}\text { A382T } \\
\text { c.799_800insA }\end{array}$ & $\mathrm{BB}$ \\
\hline 174 & German & & $\begin{array}{l}\text { F140S } \\
\text { F140S }\end{array}$ & BB \\
\hline 368 & German & Q199X & & A? \\
\hline 644 & Turkish & & $\begin{array}{l}\text { A331V } \\
\text { A331V }\end{array}$ & $\mathrm{BB}$ \\
\hline 780 & German & $\begin{array}{l}\text { T216M } \\
\text { T216M }\end{array}$ & & AA \\
\hline 781 & German & & & ?? \\
\hline 916 & German & $\begin{array}{l}\text { R567fs } \\
\text { R567fs } \\
\text { Q224X }\end{array}$ & & AA \\
\hline 1004 & German & & $\begin{array}{l}\text { G105R } \\
\text { R333W }\end{array}$ & $\mathrm{BB}$ \\
\hline 1166 & German & $\begin{array}{l}\text { T216M } \\
\text { T216M }\end{array}$ & & AA \\
\hline 1283 & German & M467T & G105R & $\mathrm{AB}$ \\
\hline 1482 & South East Europe & $\begin{array}{l}\text { R365L } \\
\text { T216M } \\
\text { c.1136+2/3delT }\end{array}$ & & AA \\
\hline 2487 & German & & & ?? \\
\hline 2778 & Dutch & $\begin{array}{l}\text { P508R } \\
\text { S547L }\end{array}$ & & AA \\
\hline $\begin{array}{l}3029 \\
3858\end{array}$ & $\begin{array}{l}\text { Turkish } \\
\text { German }\end{array}$ & $\begin{array}{l}\text { F599S } \\
\text { F599S }\end{array}$ & N203fs & $\begin{array}{l}\text { B? } \\
\text { AA }\end{array}$ \\
\hline 4057 & German & $\begin{array}{l}\text { Y397C } \\
\text { R584X }\end{array}$ & & AA \\
\hline 4289 & German & $\begin{array}{l}\text { M467T } \\
\text { D179Y }\end{array}$ & & AA \\
\hline 4611 & German & $\begin{array}{l}\text { M467T } \\
\text { Q125X }\end{array}$ & & AA \\
\hline 5335 & German & G121E & & AA \\
\hline $\begin{array}{l}5356 \\
6100 \\
6245\end{array}$ & $\begin{array}{l}\text { German } \\
\text { German }\end{array}$ & $\begin{array}{l}\text { R452W } \\
\mathrm{M} 467 \mathrm{~T}\end{array}$ & & $\begin{array}{l}\text { ?? } \\
\text { A? } \\
\text { A? }\end{array}$ \\
\hline $\begin{array}{l}6245 \\
6291\end{array}$ & $\begin{array}{l}\text { German } \\
\text { German }\end{array}$ & M467T & S421fs & $\mathrm{B}$ ? \\
\hline 6389 & German & $\begin{array}{l}\text { M123R } \\
\text { M467T }\end{array}$ & & AA \\
\hline 6670 & German & M467T & & A? \\
\hline
\end{tabular}




\section{MATERIAL AND METHODS}

The 26 patients were referred for molecular genetic testing because of (recurrent) kidney stones by external hospitals and clinicians. Patients' genomic DNA was isolated from peripheral blood samples by a simple salting-out procedure. The whole coding region and the intron/exon boundaries of SLCBA1 and SLC7A9 were amplified by PCR. Primer sequences and PCR conditions have been described previously (Botzenhart et al. 2002; Font-Llitjos et al. 2005). In case of homozygosity of rare mutations large deletions were excluded by DNA microarray analysis using the $500 \mathrm{~K}$ array system (Affymetrix, High Wycombe, UK).

\section{RESULTS AND DISCUSSION}

By screening our cohort of 26 patients with recurrent cystine kidney stones for mutations in the SLC3A1 and the SLC7A9 genes we detected mutations in $88.5 \%$ of cystinurics (Table 1). In $65.4 \%$, both alleles of an individual were affected. Homozygosity or compound heterozygosity for SLC3A1 mutations was present in 11 cystinuria patients, in another 5 cases two mutations were detectable in the SLC7A9 gene. One patient was mixed heterozygous with mutations in both genes. In 6 probands, only one mutation in one of the two genes was detectable. In 3 patients we could not detect any mutation, neither in SLC3A1 nor in SLC7A9.

On the allelic level, the detection rate was $76.9 \%$, SLC3A1 mutations accounted for $51.9 \%$, SLC7A9 mutations for $25 \%$. The most common SLC3A1 mutations were M467T and T216M in SLC3A1, G105R was the most frequent mutation in SLC7A9 (Table 2). These data confirm observations from other studies that these three mutations are indeed the most common ones (Schmidt et al. 2004; Di Perna et al. 2008).

Interestingly, two of our patients carried three mutations in the SLC3A1 gene (Table 1: patients 916 and 1482). The detection of three recessive mutations in one gene is a rare finding but it has also been known from other diseases like autosomal recessive polycystic kidney diseases (PKHD1 gene). The identification of three mutations illustrates that two mutations can be localised on the same allele, this might lead to false-positive or false-negative results in carrier diagnostics.
Table 2: Localisation and frequencies of the mutations in the SLC3A1 and SLC7A9 genes in our study cohort (new mutations are printed in bold face)

\begin{tabular}{|c|c|c|c|}
\hline Gene & Exon & Mutation & Frequencies ( $n$, \\
\hline \multirow[t]{17}{*}{$S L C 3 A 1$} & \multirow[t]{5}{*}{1} & G121E & 2 \\
\hline & & M123R & 1 \\
\hline & & Q125X & 1 \\
\hline & & D179Y & 1 \\
\hline & & Q199X & 1 \\
\hline & \multirow[t]{2}{*}{3} & T216M & 5 \\
\hline & & Q224X & 1 \\
\hline & \multirow[t]{2}{*}{ 6/Intron 6} & R365L & 1 \\
\hline & & c. $1136+2 / 3$ delT & 1 \\
\hline & 7 & Y397C & 1 \\
\hline & \multirow[t]{2}{*}{8} & R452W & 1 \\
\hline & & M467T & 6 \\
\hline & 9 & P508R & 1 \\
\hline & \multirow[t]{4}{*}{10} & S547L & 1 \\
\hline & & R567fs & 2 \\
\hline & & R584X & 1 \\
\hline & & F599S & 2 \\
\hline \multirow[t]{9}{*}{ SLC7A9 } & \multirow[t]{2}{*}{4} & G105R & 3 \\
\hline & & F140S & 2 \\
\hline & Intron 5 & IVS5+2T/C & 1 \\
\hline & \multirow[t]{2}{*}{6} & $\mathrm{~N} 203 f_{\mathrm{s}}$ & 1 \\
\hline & & c.799_800insA & 1 \\
\hline & \multirow[t]{2}{*}{10} & A331V & 2 \\
\hline & & R333W & 1 \\
\hline & 11 & A382T & 1 \\
\hline & 12 & S421fs & 1 \\
\hline
\end{tabular}

Our detection rates correspond to that published by other groups leaving $10-15 \%$ of alleles unidentified. The failure to detect mutations in single chromosomes might be explained by putative dominance of some SLC7A9 alleles, in these cases a second mutation is not needed to affect the phenotype. Furthermore, it has been suggested that genomic variants in the SLC7A9 gene might predispose a cystinuria phenotype in case of a co-occurrence with other mutations (Schmidt et al. 2003; Chatzikyriakidou et al. 2006). However, as our results and data from other groups show a reliable diagnostic screening assay for cystinuria is accessible with a detection rate of more than $85 \%$.

In clinical practice, the molecular genetic testing results might influence the prognosis and therapy of cystinuria. While homozygosity or compound heterozygosity for SLC3A1 mutations are principally associated with an increased cystine excretion, the age of kidney stone formation is difficult to predict. Indeed, in sibs with the same cystinuria genotype the age of onset can differ remarkably. Nevertheless, all carriers of two SLC3A1 or SLC7A9 mutations (genotypes AA, BB, AB) will develop kidney stones 
in their live while the majority of SLC3A1 heterozygotes do not exhibit a biochemical phenotype. In contrast, the urinary excretion pattern in heterozygote SLC7A9 mutation carriers is extremely variable and does therefore hardly allow a prediction of the clinical course, in particular in childhood.

\section{REFERENCES}

Botzenhart E, Vester U, Schmidt C, Hesse A, Halber M, Wagner C, Lang F, Hoyer P, Zerres K, Eggermann $\mathrm{T}$ 2002. Cystinuria in children: Distribution and frequencies of mutations in the SLC3A1 and SLC7A9 genes. Kidney Int, 62: 1136-1142.

Calonge MJ, Gaparini P, Chillaron J, Chillon M, Gallucci M, Rousaud F, Zelante L, Testar X, Dallapiccola B, Di Silverio F, Barcelo P, Estivill X, Zorzano A, Nunes V, Palacin M 1994. Cystinuria caused by mutations in rBAT, a gene involved in the transport of cystine. Nat Genet, 6: 420-425.

Chatzikyriakidou A, Sofikitis N, Kalfakakou V, Siamopoulos K, Georgiou I 2006. Evidence for association of SLC7A9 gene haplotype with cystinuria manifestation in SLC7A9 mutation carriers. Urol Res, 34: 299-303.

Di Perna M, Louizou E, Fischetti L, Dedoussis GVZ, Stanziale P, Michelakakis H, Zelante L, Pras E, Bisceglia L 2008. Twenty-four novel mutations identified in a cohort of 85 patients by direct sequencing of the SLC3A1 and SLC7A9 cystinuria genes. Genet Test, 12: 351-355.

Dello Strologo L, Pras E, Pontesilli C, Beccia E, RicciBarbini V, de Sanctis L, Ponzone A, Gallucci M, Bisceglia L, Zelante L, Jimenezs-Vidal M, Font M, Zorzano A, Rousaud F, Nunes V, Gasparini P, Palacin M, Rizzoni G 2002. Comparison between SLC3A1 and SLC7A9 cystinuria patients and carriers: A need for a new classification. J Am Soc Nephrol, 13: 2547-2553.

Eggermann T, Elbracht M, Haverkamp F, Schmidt C, Zerres $\mathrm{K}$ 2007. Isolated cystinuria (OMIM 238200) is not a separate entity but is caused by a mutation in the cystinuria gene SLC7A9. Clin Genet, 71: 597-598.

Font-Llitjos M, Jimenez-Vidal M, Biscegla L, Di Perna M, de Sanctis L, Rousaud F et al. 2005. New insights into cystinuria: 40 new mutations, genotype-phenotype correlation and digenic inheritance causing partial phenotype. J Med Genet, 42: 58-68.

International Cystinuria Consortium 1999. Non-type I cystinuria caused by mutations in SLC7A9, encoding a subunit (b 0,+)AT of rBAT. Nat Genet, 23: 52.

Martens K, Heulens I, Meulemans, Zaffanello M, Tilstra D, Hes FJ, Rooman R, Francois I, de Zegher F, Jaeken J, Matthijs G, Creemers JWM 2007. Global distribution of the most prevalent deletions causing hypotonia-cystinuria syndrome. Eur J Hum Genet 15: 1029-1033.

Palacin M, Goodyer P, Nunes V, Gasparini P 2001. Cystinuria. In: CR Scriver, AL Beaudet, WS Sly (Eds.): The Metabolic and Molecular Bases of Inherited Disease. $8^{\text {th }}$ Edition. Vol. III New York: McGraw-Hill, pp. 4909-4932.

Rosenberg L, Downing S, Durant J, Segal S 1966. Cystinuria: Biochemical evidence of three genetically distinct diseases. J Clin Invest, 45: 365-371.

Schmidt C, Vester U, Hesse A, Lahme S, Lang F, Zerres K, Eggermann T 2004. The population-specific distribution and frequencies of genomic variants in the SLC3A1 and the SLC7A9 genes and their application in molecular genetic testing of cystinuria. Urol Res, 32: 75-78.

Schmidt C, Tomiuk J, Botzenhart E, Vester U, Haler M, Hesse A, Wagner C, Lahme S, Lang F, Zerres K, Eggermann T, AN 2003. Genetic variations of the SLC7A9 gene: Allele distribution of 13 polymorphic sites in German cystinuria patients and controls. Clin Nephrol, 59: 353-359. 